\title{
Bionic forms in search of structural models in architecture
}

\author{
Anna Nowak,", and Wiesław Rokicki \\ Department of Structural Design, Construction and Technical Infrastructure, Faculty of Architecture, \\ Warsaw University of Technology, Koszykowa Street 55, 00-659 Warsaw, Poland
}

\begin{abstract}
Bionics is an interdisciplinary field of science, the aim of which is to create models that map processes and principles of functioning of the living organisms that can be transferred to technology. The bionic design is an interesting trend in contemporary architecture, which is characterized by the search for spatial forms in analogy to living organisms. The analyses of the possibilities to describe natural patterns using mathematical models that enable the transfer of biological structures are of particular importance. The natural patterns open up new ways to look for effective structures and materials. Shaping the forms "adapted" to the conditions, the environment and the surroundings is an element of structural design optimized in terms of working loads, which exists in accordance with the idea of a sustainable development. The paper presents the results of the research on the possibility of using mathematical models in architecture that mimic the forms found in nature and the analysis of the efficiency of bionic and geometrical forms due to the minimum weight criterion.
\end{abstract}

\section{Introduction}

The modern design process leads increasingly to a holistic approach. This type of design, which takes many aspects of the idea of sustainable development into account, is an interdisciplinary design process in which synergy solutions are sought. In this context, the bionic design that allows for the mapping of rules governing nature, functional features of biological tissues, as well as processes and structures is of particular importance in order to transfer the created models to the technology. Bionic architecture are objects adapted to the surrounding environmental conditions and constructed with minimal energy and material consumption.

\section{Possibilities of using bionic patterns in shaping structural forms}

The search for bionic patterns found in nature that can be transferred to technology is a new feature in the field of architecture modeling. Natural inspirations are possible to use in architecture e.g. by describing them using mathematical models mapping the natural form-

\footnotetext{
* Corresponding author : anna.patrycja.nowak@gmail.com, wrokicki@poczta.fm
} 
shaping processes; an analysis in the interdisciplinary design team of building biological structures; the optimization of location conditions, and material optimization.

The transfer of forms found in nature is possible due to the use of appropriate mathematical models, one of them being a catenary curve visible in slacking structures shaped under the influence of the gravitational load, an example of which is the spider's web. The shape of the curve allows you to obtain optimal stress distributions that do not break the spider thread. The catenary curve is a shape of a perfectly flexible, homogeneous and inextensible chain hanging freely between two supports in a homogeneous gravity field, which allows for an even and optimal stress distribution. The shape of the curve was described in 1691 by Gottfired Wilhelm Leibniz, Christian Huygens and Johann Bernoul as a hyperbolic cosine. [1]

Mathematical models are increasingly used in shaping the optimal structural forms under stress. An example of such shaping is the Velvet State pavilion situated in Roskilde, designed as part of the Roskilde Festival 2013 by architects from the SHJWORKS Architectural studio. The pavilion is divided into several forms and shaped as a sequence of catenary curves, which made it possible to obtain a variety of object's shape. In order to obtain a stable supporting structure, the elevation of the pavilion was constructed of bent plywood panels joined with additional polycarbonate elements.

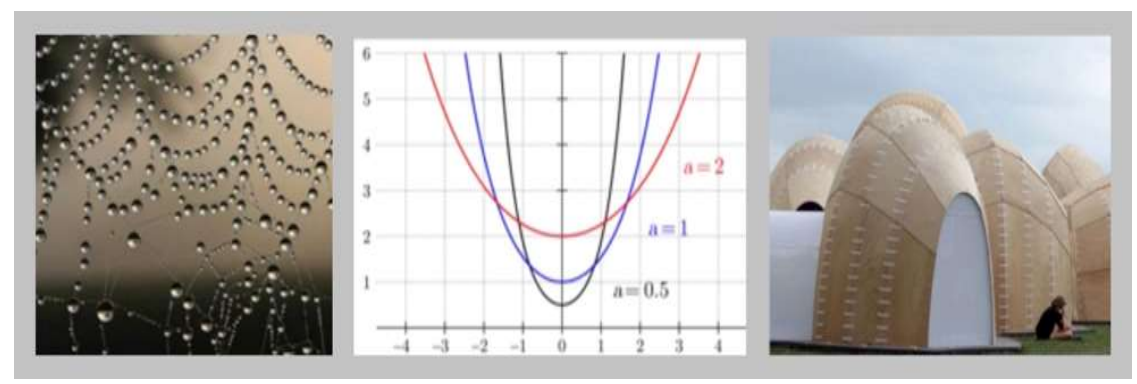

Fig. 1 On the left: A catenary curve in the shape of a spider web. Source: www.zdjecia_biz_pl / zdjecie, pajeczyna-krople_php; Center: A graph of the catenary curve function described using the hyperbolic cosine. Source: pl_wikipedia_org / wiki / krzywa_lazuchowa \# mediaviewer / FIlecatenary-pm_svg; On the right: The construction of the Velvet State pavilion designed by SHJWORKS Architectural in the form of a catenary curve. Source: http://www10.aeccafe.com/blogs / arch-showcase / 2013/08/16 / the-velvet-state-in-roskilde-denmark-by-shjworks-architectural /

An interdisciplinary research conducted in diversified research teams that allow for an accurate analysis of structures found in nature are becoming more and more important. An example of such an approach is the Research Pavilion implemented in 2015-2016 at the University of Stuttgart by scientistsfrom the Institute for Computional Design and the Institute of Building Structures and Structural Design, in collaboration with biologists from the Department of Evolutionary Biology of Invertebrates and the Department of Invertebrate Paleontology of the University of Tübingen, Germany. The structure of the Clypeasteroid ring-shaped sea urchins' shell is described on the basis of the analysis carried out using the electron microscope scanner (SEM scans). A layered structure with a diversified and complex building material was distinguished as the main features, which made it possible to obtain a lightweight and durable structure of the sea urchin's skeleton. As a result, a two-layer structure (with empty space between individual layers) was proposed from thin wooden slats, which were suitably shaped to create a double-curved, stiff shell. The individual modules were "stitched" using a numerically controlled robot, following the fibrous connections between the sea urchin slabs. The structure was subjected to structural analysis to determine the occurring stresses and structure optimization. 
One can also observe in some structural constructions the mapping of the principles of operation found in natural structures, an example of which is the tensegrity structure. Tensegrity structures are rod-tension structures dominated by stretched elements over the squeezed ones, as "Fuller" described it "squeezed elements become an island in the sea of stretching". [2], The open pavilion was designed as a tensegrity structure by Gernot Riether and Andrew Wita with students from Balle State University. Such difficult to stabilize structural elements that demonstrate the possibility of obtaining effective systems can be found, among others, in cells or skeletal-muscular systems of the human skeleton. Understanding the structures described by using the principles of physics on the example of tensegrity structures is the principle of biotensegrity, which is developed, among others, by Stephen Levin, Martin Daniele-Claude, Graham Scarr, or Donald Ingeber. [3]

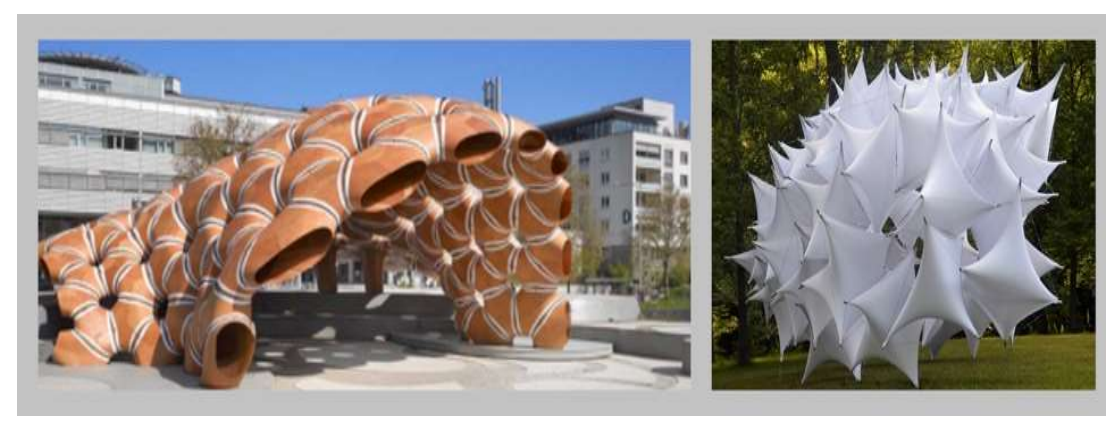

Fig. 2 On the left: Structural surface of the Research Pavilion 2016 by ICD and ITKE at the University of Stuttgart. Source: http://www.achimmenges.net/?p=5822; On the right: Tensegrity structure designed by Gernot Riether and Andrew Wit with students from Balle State University. Source: https://www.archdaily.com/553311/students-of-ball-state-construct-parametric-tensegritystructure-for-local-art-fair

The development of living organisms depends on various factors, including insolation etc., however, the biological structures are formed as a result of the affecting loads. The structural and aerodynamic analyses are of particular importance in this context. The design of aerodynamic architectural objects is visible mainly due to the architectural solutions associated with shaping the facade by looking for the appropriate form of the object and the impact of the object on the surrounding buildings. However, there are projects that also take into account the functional needs and the possibility of providing aerodynamic comfort for the users of the facility, as exemplified by the Aqua Tower jets in Chicago. As a result of the analyses, the façade was shaped accordingly to obtain an aerodynamic comfort on the balconies in a high building. By adding an organic terrace-shaped system to the classic form of a rectangular elevation, an impression similar to the limestone sedimentary forms was created and the strong wind gusts were dissipated, while the excessive air circulation (related to a significant altitude) near the façades and balconies was obtained.

Much more often, aerodynamic analyses are associated with structural calculations to reduce unfavorable pressure distribution on structural components. As a result of the research carried out, the buildings become streamlined. An example of such a design approach is the D2 skyscraper in the Paris La Défence business district. Architects Anthony Bechu and Tom Sheehan have decided to apply solutions that affect both the internal and the external structure. Through this they created a building 'cooperating' with the environment on several levels. [4]

The next step in the search for the optimization of the structure, similar to the structures found in nature, is to minimize material consumption, which is a solution consistent with the idea of sustainable development, with respect to the available materials. An example of such a design approach is the roofing of the WestendGate public space in Frankfurt am 
Main, Germany. The project was realized in 2010 by Just Burgeff architekten and a3lab as part of the renovation elements of a skyscraper with an office and hotel function known as the Marriott Hotel. The roofing design was based on biomorphic shapes describing the algorithm of growth and the formation of living organisms, mapped using a mathematical model called a Voronoi diagram. The bar structure of the roof was supported on arbor supports. Structural analyses and generated subdivisions of the roof surface in the form of Voronoi diagrams were carried out, in which the structure was subjected to optimization due to the minimum weight. As a result, the construction was made of steel pipes of the same diameter and walls three times thicker, in turn obtaining aesthetic uniformity of all construction elements, while in some places limiting the material consumption, in accordance with the occurring stresses.

Similar effects can be obtained by using more complex algorithms enabling structural optimization of structures based on the subtraction or addition of material depending on the adopted criteria. Such solutions are possible to obtain by using the Evolutionary Structural Optimization method (ESO, AESO, BESO, EESO methods). [5] This method is used to limit stresses and materials while maximizing the stiffness and effort of materials. This method was presented in the publication "A simple evolutionary procedure for structural optimization" by Mike Xie and Geir P. Steven in the 90s of the twentieth century. The tools for conducting Evolutionary Structural Optimization analyses can be used in architecture, as exemplified by the Qatar Education City Convention Center in Doha, the capital city of Qatar. The design of the architect Arat Isozaki assumed the creation of a building with a structure and form resembling trees characteristic for this area (sidra tree). The shape of the characteristic support was obtained using the EESO optimization method. The analyses were carried out by engineer Mutsuro Sasaki in order to reduce the amount of material and optimize the form of the building.

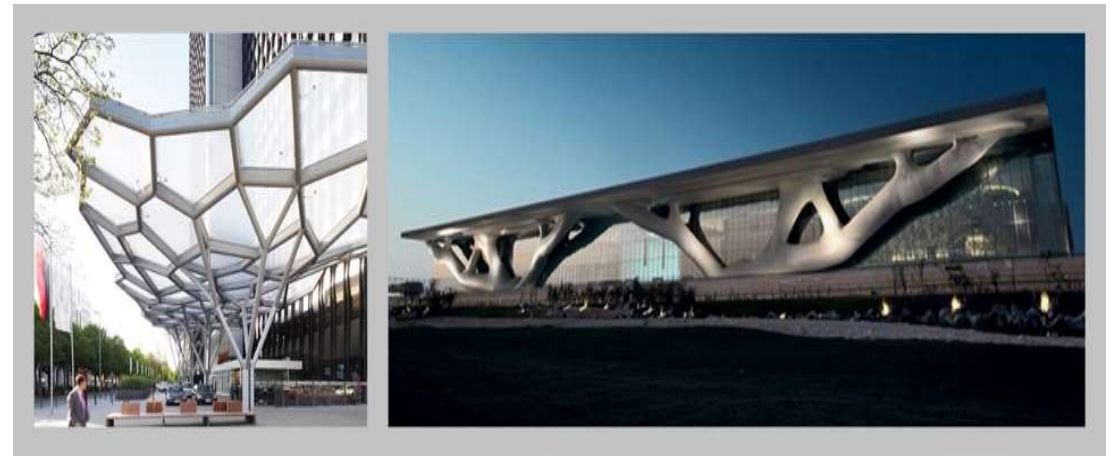

Fig. 3 On the left: Westend Gate roof in Frankfurt am Main project Just Burgeff architekten and a3lab

Source: https://www.archdaily.com/175519/westendgate-just-burgeff-architekten-a3lab; Right: Construction of the Qatar Education City Convention Center in Doha, designed by Arata Isozaki. Source: https://www.theplan.it/eng/webzine/report/qatar-national-convention-centre

\section{Model study of selected structural forms}

The main reason for the analysis was the research enabling the search for optimization due to the minimal material consumption along the lines of the structures designed by Richard Buckminster Fuller, which were moved to one of the currently undertaken architectural trends that enable shaping bionic architecture. In order to select the appropriate research models, attention has been paid to the structures visible in living organisms that "adapt" to the surrounding conditions. As a result, their shape is optimized in the period of growth due 
to the operating burdens, including hydrostatic (organisms living on the sea bottom), waves (organisms living in the tidal zone), or gravitational loads. [6]

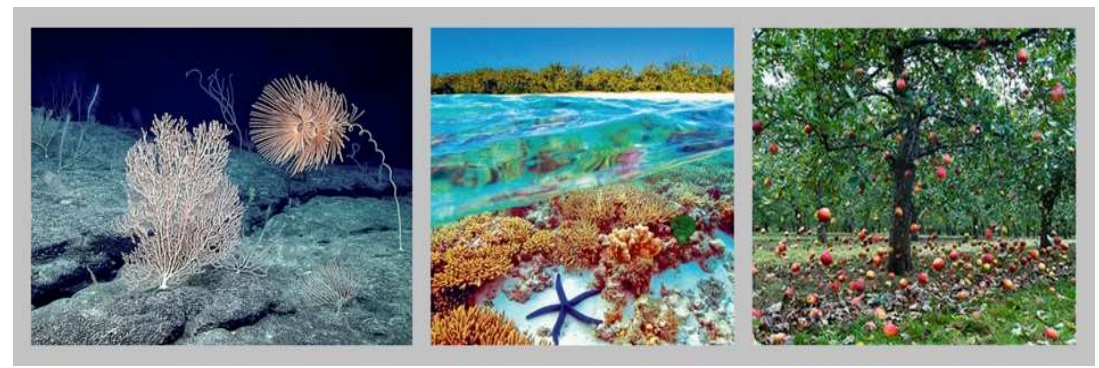

Fig.4. Structures shaped under the influence of hydrostatic loads, waves or gravitational loads. Source: ocean.si.edu/ocean-life-ecosystems/deep-ocean; www.telegraph.co.uk/news/earth/envir onment/conservation/10547035/We-must-protect-our-national-parks.html; cideruk.com/wp-content/ uploads/2016/08/fallingapplesbill-bradshaw.jpg

The type of forms found in nature was taken into consideration in the selection of examples. In nature, there are structures characterized by one axis of symmetry (lateral symmetry), multi-axis structures, but also asymmetrical structures. The research has been limited to symmetrical structures.

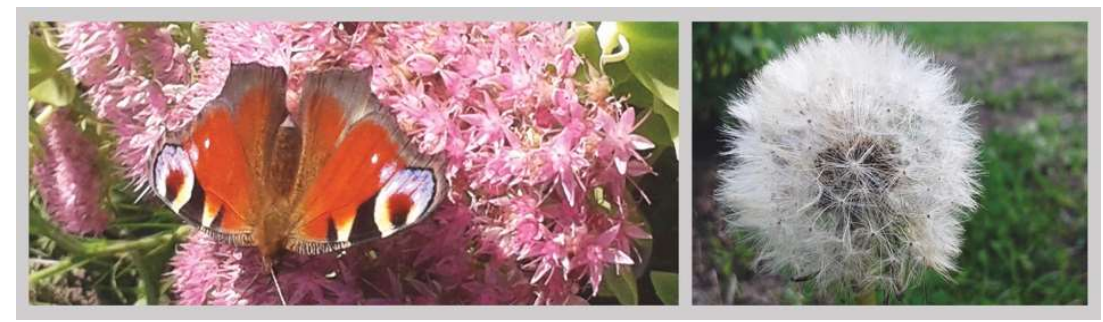

Fig. 5. Examples of side and multi-axis apparent symmetry observed in the natural world. Source: A. Nowak.

As a result, symmetrical structures shaped under the influence of various loads were chosen, among the observed structures in the natural world, which were supposed to be efficient in material use.

\subsection{Subject and scope of research}

The analyses were carried out on numerical models for selected rotational solids. The assumed static scheme of the support structure is a spatial bar structure with a base radius of 15 meters. The selection of models corresponding to the forms found in nature resulted from the search for organisms whose skeleton was shaped as a result of the gravitational or hydrostatic loads. The organic forms were mapped using mathematical models. The following were selected for research and analysis:

- $\quad$ B1 - the structure of the spider's web (the catenary curve described by the formula $\mathrm{f}(\mathrm{x})=2 \cosh (\mathrm{x} / 2))$,

- $\quad$ B2 - egg shell (elongated ellipsoid),

- B3 - Euplectella Aspergillum spine skeleton (Spline curve),

- B4 - the structure of regular sea urchins Echinus (flattened ellipsoid). 


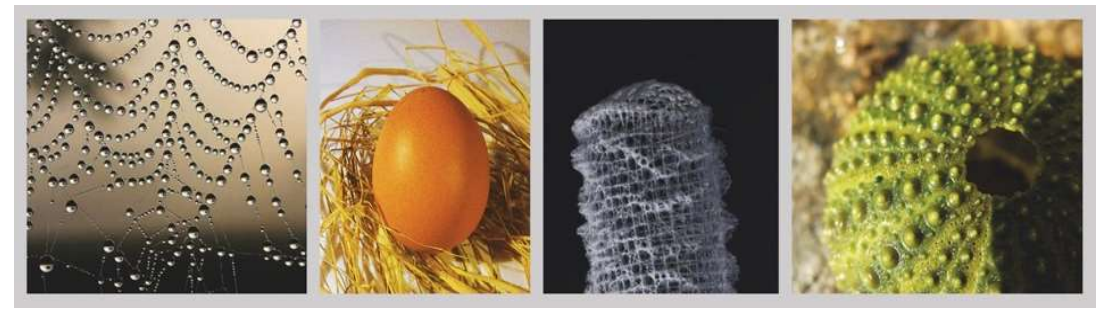

Fig. 6. Selected bionic forms for static and strength analyses. On the left: The structure of the spider's web. Source: www.zdjecia_biz_pl / zdjecie, pajeczyna - krople_php; Measure left: Egg crust. Source: A. Nowak; Center right: Sponge skeleton Euplectella aspergillum from the species Hexacitinellida. Source: http://phys.org/news/2015-04-sea-sponge-anchors-natural-strength.html; On the right: Skeleton of Echinus regular sea urchin from the Echinoidea cluster. Source: A. Nowak

For selected bionic forms, the rotational solids with different proportions have been selected which to some extent are similar to biological models. As a result:

- $\mathrm{G} 1-$ an extended paraboloid (described by the formula $\mathrm{f}(\mathrm{x})=0.5 \mathrm{x}^{2}$,

- $\mathrm{G} 2$ - elongated ellipsoid,

- $\mathrm{G} 3$ - a block created by the rotation of the Bézier curve,

- $\mathrm{G} 4$ - sphere.

The following comparable pairs of structural forms I (B1, G1), II (B2, G2), III (B3, G3), IV (B4, G4) were assumed. The adopted structural forms along with the indications are shown in the following illustration.

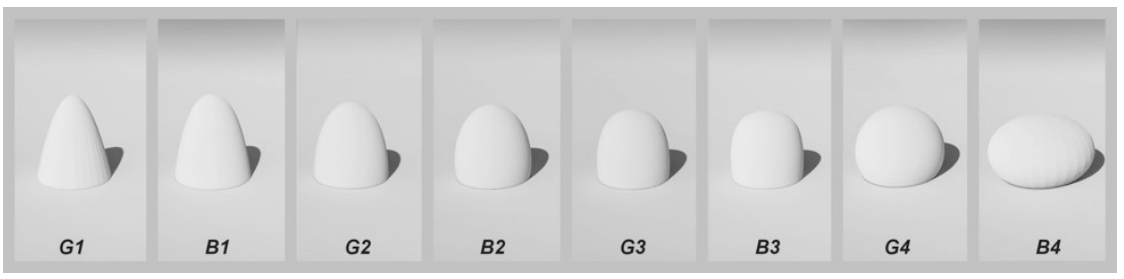

Fig. 7. The adopted structural forms. Source: A. Nowak

To make it possible to compare forms with different shapes, a homeomorphic parameter was introduced, corresponding to the homologous transformations observed among structures of common evolutionary origin. The table below presents the adopted assumptions for the conducted research. 
Table 1. Assumptions in research.

\begin{tabular}{|c|c|c|}
\hline \multicolumn{2}{|c|}{ Parameter } & Assumptions \\
\hline \multicolumn{2}{|c|}{ The homeomorphic parameter } & $\begin{array}{c}\text { Based on the proportions observed in the } \\
\text { sea urchin skeleton, the ratio of the length } \\
\text { of the curve forming to the base (span) is } \\
\text { equal to } 2.4\end{array}$ \\
\hline \multicolumn{2}{|c|}{ The grid shaping algorithm } & Equal angular divisions and bases \\
\hline $\begin{array}{l}\text { Structural grid } \\
\text { breaks }\end{array}$ & radial & $\begin{array}{l}34 \text { divisions of the base and } 14 \text { divisions of } \\
\text { the forming curve }\end{array}$ \\
\hline \multicolumn{2}{|r|}{ Range } & 30 meters \\
\hline \multirow{2}{*}{\multicolumn{2}{|c|}{ Supports }} & articulated \\
\hline & & Constant number of supports - 34 \\
\hline \multicolumn{2}{|r|}{ Material } & S235 Steel \\
\hline \multicolumn{2}{|r|}{ Profile } & $\begin{array}{l}\text { Rolled tubular profiles of circular cross- } \\
\text { section type RO }\end{array}$ \\
\hline \multicolumn{2}{|c|}{ Profile catalogue } & Katalog Polskich Profili 2007 (RPLN7) \\
\hline \multirow{4}{*}{ Load } & Dead weight & In accordance with PN-EN 1991-1:2004 \\
\hline & The load from glass panels & $\begin{array}{l}0.5 \mathrm{kN} / \mathrm{m} 2 \text { in accordance with PN-EN } \\
1991-1-1: 2004\end{array}$ \\
\hline & Operating & $\begin{array}{l}0.4 \mathrm{kN} / \mathrm{m} 2 \text { in accordance with PN-EN } \\
1991-1-1: 2004\end{array}$ \\
\hline & Wind & $\begin{array}{c}\text { Wind load was generated in Robot } \\
\text { Structural Analysis } 2017 \text { with the assumed } \\
\text { wind direction X }+ \text {, wind speed equal to } \\
20.00 \mathrm{~m} / \mathrm{s} \text { and vertical wind profile due to } \\
\text { the surrounding buildings. }\end{array}$ \\
\hline \multicolumn{2}{|c|}{ Load combination } & PN-EN 1990:2004 \\
\hline \multirow{2}{*}{$\begin{array}{l}\text { Boundary } \\
\text { conditions }\end{array}$} & Permissable deformations & $\begin{array}{c}\text { Proportion L/250 in accordance with PN- } \\
\text { EN 1990:2004 }\end{array}$ \\
\hline & $\begin{array}{c}\text { Static and endurance } \\
\text { analyses }\end{array}$ & PN-EN 1993-1:2006/NA:2010/A1:2014 \\
\hline $\begin{array}{c}\text { Quantitative } \\
\text { criteria }\end{array}$ & Parameter $\mathrm{M}_{\mathrm{p}}\left[\mathrm{kg} / \mathrm{m}^{2}\right]$ & Weight per unit of cover area \\
\hline
\end{tabular}

Depending on the adopted shape, different pressure distribution was obtained under the influence of wind load, which was generated in Robot Structural Analysis 2017.

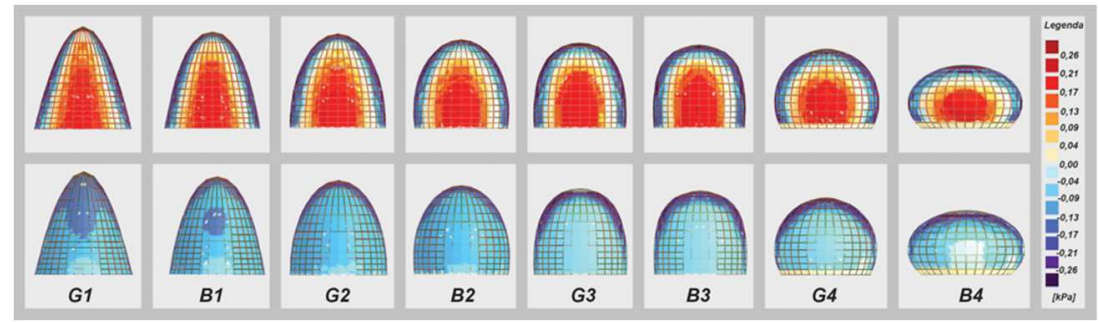

Fig. 8. Distribution of pressure on elements as a result of wind load generation in Robot Structural Analysis 2017 for assumed structural forms. At the top pressure distribution on the windward side, at the bottom on the leeward side. Source: A. Nowak

The research was carried out using modeling and simulation methods with the assistance of digital tools. Geometric forms and digital models of grid divisions were developed graphically in Graphisoft's Archicad programs and Autodesk AutoCAD software. Computational models developed for static and strength analyses were performed in Robot Structural Analysis by Autodesk using the built-in algorithm for optimizing the profile due to the minimum weight. 


\subsection{Results of the carried-out analyses}

The results of the carried-out analyses that take into account the mass efficiency of structures along with constant loads and wind are presented on the graph below.

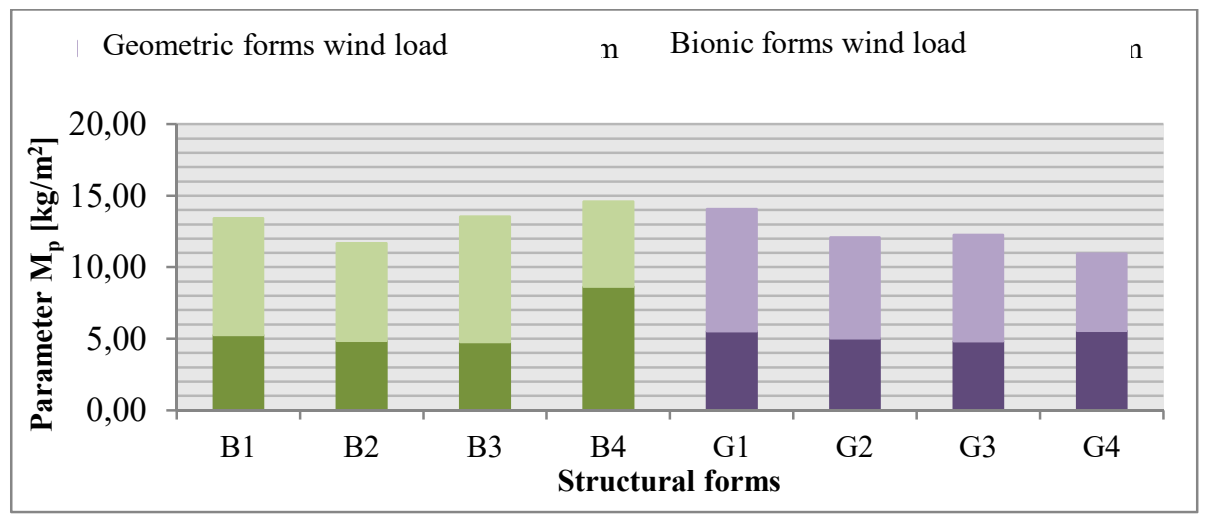

Fig. 9. Effect of shape change in all analyzed structural forms on the $M_{p}$ parameter of systems including wind load.

Among the bionic structural forms, the B2 structure imitating the egg shell is the most advantageous due to the $\mathrm{M}_{\mathrm{p}}$ parameter. The next solids with similar results are B1 forms, described by a catenary curve and B3, depicting the sponge skeleton. The heaviest structure due to the $\mathrm{M}_{\mathrm{p}}$ parameter is structure B4. Among the geometrical structural forms, the lightest structure due to the $\mathrm{M}_{\mathrm{p}}$ parameter is the G4 structure, i.e. the sphere, and the heaviest geometric form among geometrical forms is the G1 structure, described by means of a paraboloid. The most effective structural form due to the $\mathrm{M}_{\mathrm{p}}$ parameter is the geometric form G4, the similar bionic B2, and the worst B4, similar to G1.

Taking into account the variable climate loads, i.e. wind loads caused uneven mass growth for individual structural forms, which underlines the importance of shape change in structural analysis. The influence of wind load on the mass increase per unit cover area of individual forms is presented in the graph below.

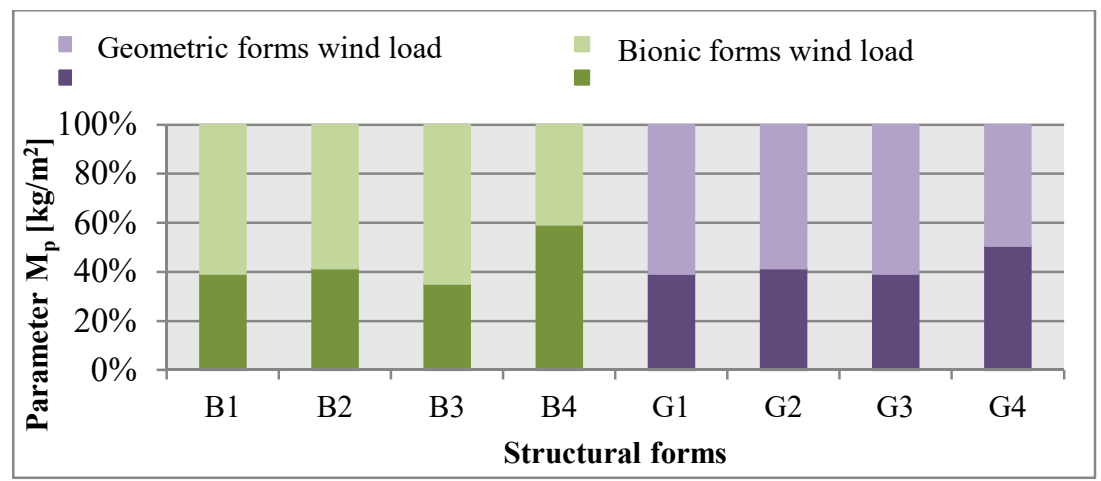

Fig. 10. Effect of wind load on efficiency due to the mass per unit area of coverage of individual bionic and geometrical structural forms.

Among the analyzed examples, some forms show susceptibility to the wind loads. The least susceptible form is the bionic structure B4 imitating the skeleton of the sea urchin, another 
geometric form G4, i.e. the sphere. The most susceptible to the impact of wind is the bionic form B3 (sponge skeleton), another is the geometric form G3 and G1, and bionic form B1.

The graph below presents a comparison of the results of analyses of the corresponding bionic and geometrical structural forms tested in the study.

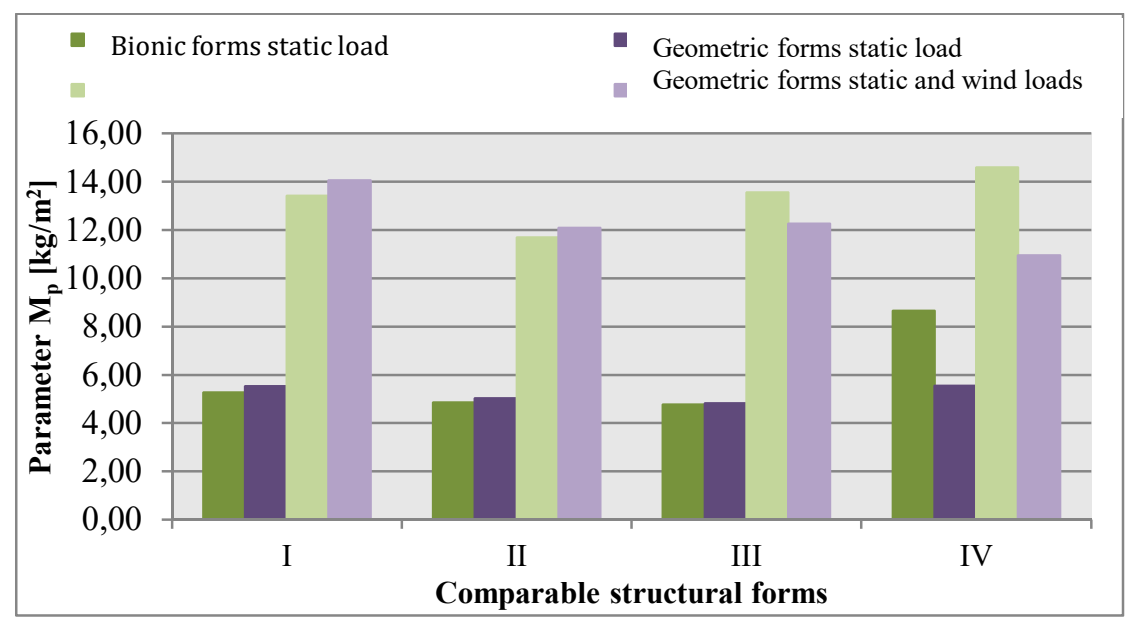

Fig. 11. Comparison of corresponding bionic and geometrical structural forms in terms of the $M_{p}$ parameter for radial grids with angular divisions of 34/14 including wind load.

In the compared pairs I and II of bionic and geometric forms, greater efficiency of forms transferred from nature is evident, both in the case of permanent loads and wind load. Pairs III and IV are the exceptions. The introduction of wind load has influenced the change of relations between forms in pair III, the remaining relations have been preserved. For B3, a larger increase in mass per unit area of coverage was observed than in the case of the G3 structure. For other pairs of structural forms, the increment is proportional. The difference of obtained results among bionic forms is smaller than in the case of geometric forms. Changes in shape in the case of geometric forms have a greater impact on the value of the $\mathrm{M}_{\mathrm{p}}$ parameter, as in the case of bionic forms.

\subsection{Conclusions from analyses}

Due to the minimum weight per unit area of the roofing the analysis results do not determine the efficiency of bionic and geometric forms, but some regularities have been observed. Among the forms the shape of which does not extend significantly above the level of the base, a greater efficiency of bionic forms with respect to their geometric equivalents is visible. This trend applies to bionic forms B1, B2 and geometric forms G1, G2. Disadvantageous differences are visible only in the case of G4 and B4 forms and in the case of solids whose shape in the gable zone is flattened, i.e. forms G3 and B3. Among these forms, the bionic form B4 is characterized by lower susceptibility to introducing climatic loads relative to the G4 structure, and on the contrary to the B3 form with respect to G3. Among other forms, the susceptibility is similar.

\section{Summary and conclusions}

Searching for inspiration and understanding the rules governing the construction of structures found in the natural world can be an important element in shaping architecture. Bionic models represent the ability to create original and optimal structures shaped under 
the influence of existing conditions. It is necessary to explore the knowledge about the functioning of organisms found in nature and ongoing processes in interdisciplinary project teams, enabling the search for synergies in technical solutions.

The comparative analysis of forms shaped by the transformations made it possible to unequivocally determine which of the rotational geometric and bionic solids constitute effective load-bearing structures as a result of taking into account the wind load. The study showed that the "bulky" structures (B4, G4) are less susceptible to wind loads, while more susceptible in those whose form in the peak zone flattens (B3, G3). In this respect, forms similar to those of the cone (B1, G1, B2, G2) are aligned. The "bulky" form of the B4 is characterized by the smallest increase in the $M_{p}$ parameter, which may be a prerequisite for the influence of non-homogeneous loads on the surface such as wind; the structures inspired by organisms living in the tidal zone could be more structurally effective.

\section{References}

1. Nowak A. Ksztaltowanie bionicznych powierzchni strukturalnych $w$ architekturze wspótczesnych elewacji. $\mathrm{PhD}$ thesis at the Faculty of Architecture of the Warsaw University of Technology (2017)

2. Bieniek Z. Budownictwo i Inżynieria Środowiska z 58 (3/11/III), Spojrzenie na rozwój i definicje systemów tensegrity. (2011)

3. Scarr G. Biotensegrity. tensegrity in biology. $<$ http://www.tensegrityinbiology.co.uk $>$ access: 30.01 .2018

4. Nowak, A. Nowe trendy w naukach inżynieryjnych. M. Kuczer (red), Aerodynamiczne badania modelowe $w$ ksztattowaniu form budynków oraz miejskich uktadów urbanistycznych (2013)

5. Zwierzycki, M. Archivolta 2, Ewolucyjne narzędzia cyfrowe $w$ formowaniu struktur przestrzennych., http://www.archivolta.com.pl/panel/dane/artykul_ 20130715183947.pdf, access: 15.10.2016 (2013)

6. Nowak A. Morfologia we współczesnej architekturze - badania modelowe form strukturalnych. Grant for young scientists and $\mathrm{PhD}$ students at the Faculty of Architecture of the Warsaw University of Technology (2017) 